\title{
REAÇÕES ALÉRGICAS MEDICAMENTOSAS NO CONSULTÓRIO ODONTOLÓGICO
}

\author{
ALLERGIC REACTIONS MEDICINAL IN DENTIST'S OFFICE
}

\author{
Cristiano Gaujac * \\ Ana Neri Oliveira " \\ Felipe Augusto Menezes Barreto " \\ Lara Mendonça Salgado * \\ Marilia Santana de Oliveira " \\ Rafaela Silva Girão
}

\begin{abstract}
RESUMO
Todas as drogas são capazes de desencadear reações tanto benéficas como nocivas. As reações adversas aos medicamentos dependem do fármaco, da dose administrada, da farmacocinética, da farmacodinâmica e da predisposição individual. As alteraçôes são bastante variáveis, incluindo desde eritema na pele até reação de anafilaxia. O tratamento dessas reaçôes compreende a retirada imediata do medicamento e a terapêutica habitual para as diferentes manifestações clínicas. O cirurgião-dentista deve conhecer o mecanismo de ação das drogas mais utilizadas no consultório odontológico, como anestésicos locais, antibióticos, analgésicos e anti-inflamatórios não esteroidais (AINES), assim poderá entender as possíveis reaçôes alérgicas medicamentosas.
\end{abstract}

DESCRITORES: Hipersensibilidade $\bullet$ Medicamentos $\bullet$ Odontologia $\bullet$ Toxidade de drogas.

\section{ABSTRACT}

All drugs are capable to unchain benefic and noxious reactions. The adverse reactions to medicines depend on the drug, dose administration, pharmacokinetic, pharmacodynamic and individual predisposition. Changes are quite variable, ranging from skin eritema to anaphylaxis reaction. The treatment of these reactions includes the immediate medication withdrawal and habitual therapy for the different clinical manifestations. The dental surgeon must know the action of the most used drugs in dentist's office, as local anesthesics, anthibiotics, analgesics and non-steroidal anti-inflammatory (NSAID), then he will be able to understand the possible alergical reactions.

DESCRIPTORS: Hypersensitivity • Drugs • Odontology • Drug toxicity.

\footnotetext{
* Professor do Departamento de Odontologia da Universidade Federal de Sergipe (UFS), Mestre em Cirurgia Bucal - cgaujac@gmail.com.

** Estudantes de Odontologia da Universidade Federal de Sergipe (UFS) - naninhanery@hotmail.com; lypebarreto@hotmail.com; lara_salgado@hotmail.com; marilia.santana@hotmail.com; rafaela_girao@hotmail.com.
} 
Gaujac C, Oliveira AN, Barreto FAM, Salgado LM, Oliveira MS, Girão RS. Reações alérgicas medicamentosas no consultório odontológico. Revista de Odontologia da Universidade Cidade de São Paulo 2009 set-dez; 21(3): 268-76

\section{INTRODUÇÃO}

A reação alérgica pode ser definida como um estado de hipersensibilidade do organismo, adquirido pela exposição primária a um determinado tipo de alérgeno (antígeno), cujo contato posterior pode produzir uma reação exacerbada. $\mathrm{O}$ número de pessoas com história de alergias não é pequeno, estimando-se que de 10 a 15 $\%$ da população possui alguma condição alérgica que requeira cuidados médicos (Andrade et.al. ${ }^{1}$ 2004).

As anafilaxias são reaçóes mediadas pelo anticorpo IgE que é produzido mediante a detecção da presença da droga ou dos seus metabólitos no organismo. Quando o antígeno se liga ao $\operatorname{IgE}$ na superfície dos mastócitos, ele libera mediadores inflamatórios. Os principais mediadores são histamina e bradicinina, responsáveis por efeitos como: vasodilatação, aumento da permeabilidade capilar, contração da musculatura lisa e aumento da atividade glandular (Araujo e Amaral $^{3}$ 2004, Becker e Reed $^{5}$ 2006).

As reações alérgicas podem ser classificadas em: Tipo I (imediata ou anafilática), desencadeia a producáo de IgE que se fixa aos mastócitos; Tipo II (citotóxica ou anticorpo-dependente), mediada por anticorpos citotóxicos IgM e IgG; Tipo III (mediada por complexos); e Tipo IV (dermatite de contato), mediada por celulas $\mathrm{T}$, dendríticas, macrófagos e citoquinas. A classificação das reações de hipersensibilidade é feita de acordo com a resposta do sistema imunológico. Sabe-se que os anestésicos locais são capazes de provocar reaçóes de hipersensibilidade dos tipos I e IV. Os ésteres podem provocar hipersensibilidade do Tipo I, enquanto as amidas podem provocar as hipersensibilidades do Tipo I e IV (Araujo e Amaral $^{3}$ 2004, Dale et al. ${ }^{13} 2001$ Canfield ${ }^{10}$ 1987).

As reaçóes alérgicas, de acordo com a intensidade da sua resposta, podem ser localizadas ou generalizadas. As localizadas (cutâneas) são caracterizadas por sinais como eritemas ( vermelhidão da pele), urticária, prurido (coceira) e o aparecimento de pápulas (rash cutânea). Nas reações generalizadas, além das alteraçôes cutâneas, podem ser observados o broncoespasmo, edema de laringe, hipotensão arterial e colapso vasomotor, que trazem risco potencial de vida ao paciente e por isso mesmo devem ser rapidamente diagnosticadas e tratadas (Andrade et.al. ${ }^{1}$ 2004).

O cirurgiáo-dentista deve conhecer o mecanismo de ação de fármacos utilizados em seu dia a dia, para lidar com possíveis complicaçóes que esses medicamentos possam causar. Assim, ele poderá minimizar os riscos do emprego de tais fármacos a pacientes que possuam, ou não, alguma condição limitante na saúde. $\mathrm{O}$ objetivo deste artigo é esclarecer aos profissionais de Odontologia a extrema importância do conhecimento das possíveis reações alérgicas das drogas mais comumentes utilizadas na prática odontológica (Antunes et al. ${ }^{2}$ 2007, Loureiro et al. ${ }^{23}$ 2004).

\section{REVISÃO DE LITERATURA}

Reaçôes alérgicas ou de hipersensibilidade podem ser definidas como eventos adversos náo decorrentes de propriedades toxicológicas conhecidas do medicamento, porém, que são originadas de reações imunológicas ao fármaco ou aos seus metabólitos (Nagao-Dias et al. ${ }^{27}$ 2004). Cerca de $1 / 3$ das reaçóes adversas são representadas pelas reaçóes alérgicas e aparecem como causa importante de morbidade e mortalidade.

A reaçáo do Tipo I envolve a reaçáo de anafilaxia mediada por anticorpos específicos derivados da imunoglobulina $\mathrm{E}$ (IgE) associados a mastócitos e basófilos que provocam a liberação de histamina e de outros mediadores químicos que geram reaçóes inflamatórias (Roberts e Sowray ${ }^{30}$ 1995, Canfield et al. ${ }^{10}$ 1987) Nagao-Dias et al. ${ }^{27}$ 2004). Os efeitos desse tipo de hipersensibilidade podem ser locais, limitando-se às vias aéreas superiores (fase inicial da asma), à pele (urticária) e ao trato gastrintestinal. Já em outros casos a reação é mais generalizada, podendo chegar a um choque anafilático (Dale et al. ${ }^{13}$ 2001).

O Tipo II ou citotóxico anticorpo-dependente ocorre quando há prejuízo nos tecidos pelo fato das células conterem em suas superfícies antígenos que combinam com anticorpos produzindo lise (destruição de antígenos) e morte celular por mecanismos de atuação do sistema complemento ou de citotoxidade celular mediada por anticorpos (Canfield et al. ${ }^{10}$ 1987, Nagao-Dias et al. ${ }^{27}$ 2004). São exemplos dessa hipersensibilidade as alterações produzidas por drogas nos neutrófilos polimorfonuclares resultando em agranulocitose e nas plaquetas pode levar ao aparecimento da púrpura trombocitopênica (Dale et al. ${ }^{13}$ 2001).

O Tipo III ocorre quando o anticorpo reage com o antígeno. $\mathrm{O}$ complexo formado entre eles pode ativar o complemento ou fixar-se aos mastócitos e estimular a liberação de mediadores. A hipersensibilidade do Tipo III também está implicada no lúpus eritematoso sistêmico, o qual é uma doença inflamatória autoimune crônica do tecido conjuntivo (Dale et al. ${ }^{13}$ 2001, Nagao-Dias et al. ${ }^{27}$ 
Gaujac C, Oliveira AN, Barreto FAM, Salgado LM, Oliveira MS, Girão RS. Reações alérgicas medicamentosas no consultório odontológico. Revista de Odontologia da Universidade Cidade de São Paulo 2009 set-dez; 21(3): 268-76

2004)

A hipersensibilidade Tipo IV ou hipersensibilidade retardada envolve a proliferação e danos aos tecidos devido à liberação de linfocinas. As respostas imunes são locais e mediadas por células. Esse tipo de hipersensiblidade é causado pela interação do antígeno com linfócitos $\mathrm{T}$ inflamatórios e ou citotóxicos na ausência de anticorpos. A dermatite alérgica ou de contato é uma manifestação do Tipo IV (Campbell et al..$^{9} 2001$, Canfield et al. ${ }^{10}$ 1987, Nagao-Dias et al. ${ }^{27}$ 2004).

As manifestaçôes clínicas das reações alérgicas variam dependendo do mecanismo imunológico e do órgáo acometido. Os fatores de risco para o aparecimento das reaçôes alérgicas são os componentes genéticos, idade do paciente, histórias das reaçôes cruzadas, potência e imunogenicidade do fármaco (Araujo et al. ${ }^{4}$ 2005). Dessa maneira é essencial que os profissionais de Odontologia conheçam os mecanismos de ação das drogas mais utilizadas na clínica.

\section{Mecanismo de açáo dos fármacos}

\section{Anestésicos}

Todas as cirurgias odontológicas, em nível ambulatorial, são realizadas sob anestesia local, por esse motivo é fundamental um conhecimento sobre os mecanismos de ação e as reações alérgicas que esse tipo de medicamento desencadeia. Os anestésicos locais exercem seus efeitos pela depressão da excitação das terminações nervosas ou pela inibição do processo de conduçáo nos nervos periféricos. Esses anestésicos deslocam os íons cálcio do sítio receptor dos canais de sódio, o que permite a ligação da molécula de anestésico ao sítio, produzindo bloqueio do canal de sódio e diminuindo a condutância do sódio que reduz a taxa de despolarização elétrica e leva a uma falha em obter o nível de potencial limiar juntamente com falta de desenvolvimento dos potenciais de ação propagados, bloqueando a condução (Malamed ${ }^{24}$ 2005, Villaça e Abede Junior ${ }^{32}$ 1999).

Os anestésicos locais podem ser classificados em amida ou éster. A hipersensibilidade ao anestésico do tipo amida é rara, já ao do tipo éster é mais frequente (Becker e Reed ${ }^{5}$ 2006, Malamed ${ }^{24}$ 2005, Kalghatgi et al. ${ }^{21}$ 2001). $\mathrm{Na}$ maioria dos casos, as reaçóes alérgicas não são propriamente devidas ao anestésico, podendo ocorrer devido aos seus constituintes como os vasoconstritores, antioxidantes (metabissulfito de sódio) e conservantes que são usados para aumentar o tempo de armazenamento, tendo-se como exemplo o metilparabeno. Os bissulfitos são antioxidantes, encontrados em todos os tubetes de anestésicos que contêm vasoconstritor; as pessoas com alergia aos bissulfitos podem desenvolver uma resposta grave (broncoespasmo) (Campbell et al. ${ }^{9}$ 2001, Malamed $\left.^{24} 2005\right)$.

As manifestações clínicas das reaçóes alérgicas variam de respostas leves e tardias, até reaçóes imediatas e letais, que se desenvolvem imediatamente após a exposição ao anestésico. As respostas alérgicas incluem urticária, taquicardia, angioedema, hipotensão, broncoespasmo, anafilaxia sistêmica. De fato, as respostas alérgicas com risco relacionadas ao anestésico local são raras. A reação alérgica mais comum devido ao uso dos anestésicos é a urticária e angioedema (Araujo e Amaral $^{3}$ 2004, Malamed $^{24}$ 2005).

\section{Analgésicos}

As principais classes dos analgésicos são os não opioides (ou não narcóticos) e os opioides (ou narcóticos). A escolha do melhor analgésico a ser adotado vai depender da intensidade da dor provocada pelo tratamento, doença ou lesão. Os analgésicos não opioides incluem a dipirona, o paracetamol, os AINEs e a aspirina (salicilato). Essas drogas são usados para dores orofaciais agudas, musculoesqueléticas de leves a moderadas (Andrade et.al. ${ }^{1}$ 2004, Gaujac ${ }^{18}$ 2006, Grisi et al. ${ }^{19}$ 1998).

A dipirona e o paracetamol pertencem ao grupo de substâncias analgésicas e antitérmicas, porém não atuam como anti-inflamatórios, e são atualmente os fármacos mais comercializados no país. Já a aspirina e os AINEs têm ação anti-inflamatória, antipirética e analgésica. Um fator comum entre estes agentes é sua atuação como supressores de prostaglandinas nos nociceptores periféricos, através do bloqueio da cicloxigenase (COX). As enzimas $\mathrm{COX}$ demonstram exercer um papel central nas reaçôes de hipersensibilidade, sendo mais comuns as reaçôes anafilactoides. No entanto, esses fármacos podem ser ineficazes em algumas situaçóes de dor intensa, tendo que ser feita a substituição por drogas mais potentes, como é o caso dos analgésicos de açáo central, os opioides (Andrade et.al. ${ }^{1}$ 2004, Nagao-Dias et al. ${ }^{27}$ 2004, Gaujac $^{18}$ 2006, Sobreira e Zampier ${ }^{31}$ 1999, Ribeiro e Rosário $^{29}$ 1992).

Os analgésicos opioides são fármacos que produzem efeitos semelhantes à morfina, e incluem tanto agentes naturais quanto sintéticos e são únicos em sua capacidade de reduzir dores moderadas e severas. Seus efeitos no sistema nervoso central incluem analgesia, sedação e 
Gaujac C, Oliveira AN, Barreto FAM, Salgado LM, Oliveira MS, Girão RS. Reações alérgicas medicamentosas no consultório odontológico. Revista de Odontologia da Universidade Cidade de São Paulo 2009 set-dez; 21(3): 268-76

sonolência. Em nível celular os receptores opioides, pertencentes às família dos receptores acoplados às proteína $\mathrm{G}$, inibindo a adenilato ciclase, que proporciona a diminuição do conteúdo intracelular de adenosina monofosfato cíclico (cAMP) (Dale et al. ${ }^{13} 2001$, Fang et al. ${ }^{16}$ 1996, Grisi et al. ${ }^{19}$ 1998).

Dessa maneira, os opioides exercem o papel de promoção da abertura dos canais de cálcio regulados por voltagem, reduzindo a excitabilidade dos neurônios, como a liberação dos transmissores, tendo efeito global inibitório na célula. O que ocorre nos receptores opioides determina, assim, o mecanismo de ação, as propriedades clínicas e os efeitos adversos, que incluem reaçóes de hipersensibilidade pouco comuns envolvendo estes medicamentos. $\mathrm{O}$ efeito mais comum é a depressão respiratória (não relacionada à hipersensibilidade), porém, os opioides também são capazes de gerar reaçóes que envolvem liberação de hitamina (Dale et al. ${ }^{13}$ 2001, Nunes $^{28}$ 2008, Grisi et al. ${ }^{19}$ 1998, Bricks e Silva ${ }^{6}$ 2005).

As reaçóes de anafilaxia que mais ocorrem entre os analgésicos não opiodes são angioedemas, urticárias, reações sistêmicas e broncoespasmos (mais comuns em pacientes asmáticos). No caso dos medicamentos opioides

as reações relatadas são: prurido (reação leve), a vasodilatação e hipotensão, e o brancoespasmo, principalmente em pacientes com hipovolemia e choque. (NagaoDias et al..$^{27}$ 2004, Grisi et al. ${ }^{19} 1998$, Ribeiro e Rosário ${ }^{29}$ 1992).

\section{Anti-inflamatórios não esteroidais (AINES)}

Os AINES, em sua maioria, apresentam três efeitos: Anti-inflamatórios, analgésicos para dor leve e moderada e antipiréticos (Dale et al. ${ }^{13}$ 2001). Eles são inibidores da cicloxigenase (COX), uma das vias de metabolização do ácido araquidônico que gera prostaglandinas como produto final, por conseguinte há uma redução da síntese de prostranoides (Andrade et.al. ${ }^{1}$ 2004, Gaujac ${ }^{18}$ 2006, Sobreira e Zampier ${ }^{31}$ 1999, Chahade et al. ${ }^{11}$ 2008). Sua ação anti-inflamatória decorre da redução de prostaglandinas vasodilatadoras (PGI1 e PGI2), que estão associadas à vasodilatação, diminuindo assim a formação de edema (Dale et al. ${ }^{13}$ 2001).

Os AINES convencionais são inibidores de ambas as izoenzimas COX1 e COX2, sendo que a inibição da COX1 era a maior responsável pelos efeitos indesejáveis observados (gastrintestinais, hepáticos, cardiovasculares, renais, hematológicos etc) (Dale et al. ${ }^{13}$ 2001, Chahade et al. ${ }^{11}$ 2008, Bricks ${ }^{7}$ 1998). Nimesulida, etodolaco e meloxican fizeram parte da primeira geração de AINES seletivos para a COX2, que reduziram bastante os efeitos colaterais causados pela inibição da COX1. Outros fármacos muito importantes são os COXIBs de segunda geração (celecoxib, paracoxib, etoricoxib, valdecoxib e lumiracoxib) que têm proporcionado menor desconforto gastrintestinal do que os AINES convencionais (Gaujac $^{18}$ 2006). Em contrapartida, observouse que eles vêm causando efeitos colaterais mais graves como arritmias cardíacas, e estão caindo em desuso, devendo ser ministrados apenas em pacientes com problemas gástricos graves (Sobreira e Zampier ${ }^{31}$ 1999).

As possíveis reações alérgicas causadas pelos AINES incluem tanto reaçóes cutâneas, envolvendo urticária e edema, quanto reações cruzadas respiratórias, como asma e rinoconjuntival. Tais alergias estão ligadas ao efeito comum de inibição da cicloxigenase pelo ácido acetilsalicílico (AAS) e AINES (Ribeiro e Rosário ${ }^{29}$ 1992).

\section{Antibióticos}

Os antibióticos agem sobre bactérias patogênicas susceptíveis, interrompendo seu crescimento e reprodução (efeito bacteriostático) e/ou induzindo a morte bacteriana (efeito bactericida, bacteriolítico). Esses efeitos ocorrem através da interferência sobre as vias metabólicas desses agentes infecciosos que podem alterar desde a permeabilidade (membrana externa) até a síntese (parede celular, ácido fólico, DNA, RNA e proteínas) dessas bactérias (Dale et al. ${ }^{13}$ 2001, Grumach e Rosário ${ }^{20} 2000$, Ferreira ${ }^{17}$ 2007).

As penicilinas e cefalosporinas inibem a síntese da parede celular, competindo ou inibindo as enzimas participantes da síntese. A parede celular não é sintetizada devido à não formação de seus constituintes, o que poderá levar a um desequilíbrio e à ação de autolisinas destruindo as bactérias. A ação dos antibióticos sobre a membrana celular se desenvolve quando se ligam aos constituintes normais da membrana causando uma desorganização funcional, já que modificações na permeabilidade podem comprometer o metabolismo da célula. A membrana pode, ainda, sofrer alteraçôes nos seus constituintes, quando sujeita à ação dos antimicrobianos (Andrade et.al. ${ }^{1}$ 2004, Grumach e Rosário ${ }^{20}$ 2000, Ferreira $^{17}$ 2007).

Os antibióticos também podem atuar sobre diversas etapas da síntese protéica bacteriana, sendo que os ribossomos são a estrutura alvo, pois, devido à sua constituição diferente, são responsáveis pela toxidade seleti- 
Gaujac C, Oliveira AN, Barreto FAM, Salgado LM, Oliveira MS, Girão RS. Reações alérgicas medicamentosas no consultório odontológico. Revista de Odontologia da Universidade Cidade de São Paulo 2009 set-dez; 21(3): 268-76

va dos antibióticos. Entretanto, a mitocôndria humana também possui ribossomos, podendo sofrer a ação de alguns desses antibióticos (Grumach e Rosário ${ }^{20} 2000$, Ferreira $^{17}$ 2007).

A atividade enzimática específica de um microrganismo pode ser inibida também competitivamente por antimetabólitos que se assemelham muito ao substrato normal da enzima como as sulfonas e o trimetroprim na síntese do ácido fólico. A maioria dos antibióticos que agem sobre a replicação do DNA não apresenta toxicidade seletiva, afetando as células humanas, como é o caso da mitomicina. Outros são empregados na terapêutica como griseofulvina, novobiocina e as quinolonas (Grumach e Rosário ${ }^{20} 2000$ Ferreira $^{17}$ 2007).

Apesar de haver uma grande variedade de antimicrobianos, os fármacos â-lactâmicos, principalmente penicilinas e cefalosporinas, são os antibióticos mais utilizados e os responsáveis pela maior parte das alergias a medicamentos (Nagao-Dias et al. ${ }^{27}$ 2004). Embora a reação alérgica pela penicilina possa ser desencadeada por qualquer via de administração, a aplicação local (tópica), comparativamente à oral, é a que apresenta maior incidência de sensibilização (Andrade et.al. ${ }^{1}$ 2004).

Os principais efeitos indesejáveis das penicilinas consistem em reaçóes de hipersensibilidade, causadas pelos produtos de degradaçáo da penicilina que se combinam com a proteína do hospedeiro e tornam-se antigênicos (Marzola ${ }^{25}$ 1999). Essas reaçóes podem ser divididas em reaçôes imediatas, reações aceleradas e reaçóes tardias. As reaçóes imediatas são consideradas as mais graves, ocorrem até 20 minutos após a administração de penicilina por via parenteral e até 1 hora após a administração oral. Constituem-se em urticária, prurido difuso, rubor cutâneo e, em menor frequência, edema laríngeo, arritmia cardíaca e choque. O choque anafilático é raro e em alguns casos pode ser fatal, pois tem a possibilidade de desenvolver insuficiência cardiovascular e respiratória (Grumach e Rosário ${ }^{20}$ 2000, Marzola ${ }^{25}$ 1999).

\section{Tratamento das reaçóes alérgicas}

As reaçóes cutâneas podem ser desencadeadas por anestésicos locais, AINES, analgésicos e antibióticos, se apresentando das seguintes maneiras: urticária, angioedema e erupçôes cutâneas. A urticária está relacionada a pápulas, que são placas de pele elevadas, lisas e com frequência há prurido. $\mathrm{O}$ angioedema é um edema localizado, em resposta a um alérgeno. Ele atinge com mais frequência a face, mãos, pés e genitália. As erupções po- dem decorrer de anticorpos, mas geralamente são mediadas por células, e variam de erupçóes cutânes simples até esfoliaçõos mais graves. As reações cutâneas alérgicas são as mais simples, caso sejam as únicas manifestaçóes clínicas não são letais, porém se aparecerem logo após a administração podem indicar uma reação mais generalizada (Dale et al. ${ }^{13}$ 2001, Bricks ${ }^{7}$ 1998, Criado et al. ${ }^{12}$ 2004).

Para o tratamento das reaçóes cutâneas, a primeira ação a ser tomada é a suspensão imediata do medicamento e terapêutica habitual para as diferentes manifestações clínicas. As medidas de tratamento para as reaçóes cutâneas imediatas e tardias começam posicionando-se o paciente de forma que ele se sinta confortável, e é preciso fazer a avaliação dos sinais vitais (frequência cardíaca e respiratória). Depois administra-se 1 ampola de prometazina $50 \mathrm{mg}$ e 1 ampola de betametazona $4 \mathrm{mg}$, por via intramuscular. A monitoração do paciente deve ser feita durante 20 a 30 minutos. Caso o quadro se mantenha estável, prescreve-se anti-histamínico por via oral e dispensa-se o paciente, acompanhado por alguém (Andrade et.al. ${ }^{1}$ 2004, Fang et al. ${ }^{16}$ 1996, Marzola ${ }^{25}$ 1999).

Ao perceber a queda evidente da pressáo arterial, posiciona-se o paciente de forma que fique deitado de costas, com os pés ligeiramente elevados (posição de Tredenlenburg). Solicita-se um serviço médico, e, enquanto isso, administra-se $0,3 \mathrm{ml}$ de adrenalina $(1: 1000)$ ou $0,5 \mathrm{ml}$ de epinefrina aquosa $(1: 1000)$ via subcutânea, Mantendose o controle dos sinais vitais do paciente. Um mesmo volume de adrenalina pode ser administrado a cada 5 ou 10 minutos. Caso os sintomas desapareçam, administrase uma ampola de anti-histamínico por via intramuscular (Andrade et.al. ${ }^{1}$ 2004, Fang et al. ${ }^{16}$ 1996).

Anestésicos locais e AINES podem ocasionar broncoespasmos que se caracaterizam pela obstrução reversível das vias aéreas, resultante da constrição dos músculos lisos que revestem os brônquios (Fang $e t a l .{ }^{16}$ 1996). O tratamento incia-se inclinando o posicionamento da cadeira, e na presença de cianose solicita-se socorro médico de urgência e instituem-se as médidas de suporte básico à vida. A continuidade do tratamento é feito administrando-se 1 ou 2 aplicaçóes de um broncodilatador na forma de aerossol (salbutamol), podendo também ser administrada adrenalina, a qual age sobre a musculatura lisa das vias respiratórias, tendo assim efeito broncodilatador. Em seguida institui-se oxigênio num fluxo de 5 a 7 litros por minuto (Andrade et.al. ${ }^{1}$ 2004).

Choque Anafilático é um tipo de resposta de hiper- 
Gaujac C, Oliveira AN, Barreto FAM, Salgado LM, Oliveira MS, Girão RS. Reações alérgicas medicamentosas no consultório odontológico. Revista de Odontologia da Universidade Cidade de São Paulo 2009 set-dez; 21(3): 268-76

sensibilidade do Tipo I. É uma reação súbita e potencialmente fatal, resultando na liberação de histamina e outros mediadores. As principais características são: erupçóes urticariformes, edema do tecido mole, broncoconstrição e hipotensão. Apesar de as reações anafilactoides de início súbito serem raríssimas, todos os medicamentos utilizados na prática odontológica são propícios a desencadear esse tipo de reação. As penicilinas são as drogas com maior potencial para causar reaçóes anafiláticas e são responsáveis por aproximadamente $75 \%$ das mortes por anafilaxia (Fang et al. ${ }^{16}$ 1996, Marzola ${ }^{25}$ 1999).

Para o tratamento inicial do choque anafilático que evolui com insuficiência cardiovascular, deve-se administrar $0,5 \mathrm{ml}$ de epinefrina aquosa $(1: 1000)$, por via subcutânea, se não houver hipotensão; em caso de hipotensão, injetar por via endovenosa. Se necessário, repetir o procedimento a cada 5 ou 10 minutos. O cirurgião- dentista deve manter o suporte cardiovascular, monitorando cuidadosamente os sinais vitais, checando a regularidade do pulso para monitorar as arritmias e, em casos de hipotensão, colocar o paciente em posição supina na cadeira e elevar as extremidades inferiores (posição de Trendelenburg) (Mertes e Laxinaire ${ }^{26}$ 2004, Malamed ${ }^{24} 2005$, Fang et al. ${ }^{16}$ 1996, Escobar et al. ${ }^{15}$ 1998, Brito et al. ${ }^{8}$ 2008, Duarte et al. ${ }^{14}$ 2008).

O controle da insuficiência respiratória deve-se iniciar com o estabelecimento de um suporte respiratório, como, por exemplo, ventilaçáo boca a boca ou máscara com oxigênio a $100 \%$. O tratamento subsequente seria a aplicação de agentes beta-adrenérgicos, que são as drogas de primeira linha no tratamento emergencial nas paradas respiratórias, corticoides que atuam diminuindo a reação do sistema imune e por fim anticolinérgicos (Dale et al. ${ }^{13}$ 2001, Fang et al. ${ }^{16}$ 1996, Escobar et al..$^{15}$ 1998).

\section{DISCUSSÃO}

Reaçôes alérgicas ou de hipersensibilidade podem ser definidas como eventos adversos não decorrentes de propriedades toxicológicas conhecidas do medicamento, porém, que são originadas de reaçôes imunológicas ao fármaco ou aos seus metabólitos. Os fatores de risco para o aparecimento das reações alérgicas são os componentes genéticos, idade do paciente, histórias das reaçóes cruzadas, potência e imunogenicidade do fármaco. Ao perceber o aparecimento de alguma reação alérgica, o cirurgião-dentista deve interromper a administração do fármaco imediatamente e substituí-lo por outro que não provoque tais reaçôes e atenda às necessidades do pacien- te (Nagao-Dias et al. ${ }^{27}$ 2004).

Embora a hipersensibilidade dos anestésicos locais seja rara, é importante obter o conhecimento de suas respostas alérgicas, já que ele é utilizado nas cirurgias odontológicas. Além do próprio anestésico, deve-se também ter atenção em relação a seus constituintes, tais como, vasoconstritores, conservantes e antioxidantes, pois há uma concordância entre as referências que afirmam serem estes os principais causadores das reaçóes alérgicas (Becker e Reed ${ }^{5}$ 2006, Campbell et al. ${ }^{9}$ 2001, Malamed ${ }^{24}$ 2005, Kalghatgi et al. ${ }^{22}$ 2001).

As reações que envolvem analgésicos acometem com maior frequência os analgésicos não opioides. De acordo com Ribeiro et al. $^{29}$ (2000), a principal causa de reação à droga é a ingestão de AAS e AINE. As reaçóes aos analgésicos ocorrem mais em atópicos e apontam igual proporção quanto à ocorrência em crianças e adultos afetados. O broncoespasmo demonstra afetar mais comumente pessoas que apresentam histórico de asma. É possível afirmar que os analgésicos opioides desenvolvem reaçóes de hipersensibilidade, mas estas se apresentam com menor frequência (Nagao-Dias et al. ${ }^{27}$ 2004, Ribeiroet al. ${ }^{29}$ 1992).

Os antibióticos B-lactâmicos, principalmente penicilinas e cefalosporinas são os responsáveis pela maior parte das alergias. Contudo, esses antibióticos não apresentam toxicidade no ser humano, pois agem seletivamente sobre a parede celular do microrganismo. Como essa estrutura é ausente nas células do hospedeiro, esse não desenvolve toxidade. Os demais antibióticos são menos alérgicos, porém apresentam uma maior toxicidade por agirem sobre estruturas tais como membrana celular, ribossomos e DNA (Nagao-Dias et al. ${ }^{27}$ 2004).

É preciso destacar que cabe ao cirurgião-dentista ter em seu consultório kits de primeiros socorros e saber qual a melhor conduta para casos de reações alérgicas. $\mathrm{O}$ profissional deve estar preparado para situaçóes de emergência. Os principais itens para tais casos são os antihistamínicos, corticosteroides, adrenalina, seringas e cilindros de oxigênio suplementar (Andrade et.al. ${ }^{1}$ 2004, Loureiro et al. ${ }^{23}$ 2004, Nagao-Dias et al. ${ }^{27}$ 2004, Ribeiro et al. ${ }^{29}$ 1992).

Existe uma controvérsia na administração do vasoconstritor no tratamento do choque anafilático. Fang et al. ${ }^{16}$ (1996) afirmam que o volume de epinefrina administrado seria de $0,5 \mathrm{ml}(1: 1000)$, por via subcutânea. No entanto, Marzola ${ }^{25}$ (1999) contradiz, afirmando que a quantidade necessária para a administração é de $0,2 \mathrm{ml}$ 
Gaujac C, Oliveira AN, Barreto FAM, Salgado LM, Oliveira MS, Girão RS. Reações alérgicas medicamentosas no consultório odontológico. Revista de Odontologia da Universidade Cidade de São Paulo 2009 set-dez; 21(3): 268-76

de solução de adrenalina (1:1000) embutido no antihistamínico. Já Andrade et.al. ${ }^{1}$ (2004) e Hupp et al. ${ }^{21}$ (2000) afirmam que a quantidade de adrenalina necessária deverá ser de $0,3 \mathrm{ml}(1: 1000)$.

O protocolo estabelecido pela clínica deve levar em consideração o conhecimento de uma possível ocorrência de alergias já desenvolvidas pelo paciente, sabendo ou não qual a sua causa. Nesses casos, administra-se por via oral 4 ou $8 \mathrm{mg}$ do corticoide (dexametasona) no préoperatório, caso não haja contraindicação. Esse procedimento reduz a possibilidade de reação, pois diminui a atividade imunológica do paciente propiciando, assim, a atenuação das possíveis manifestaçôes alérgicas que possam ser desenvolvidas (Andrade et.al. ${ }^{1}$ 2004, Marzola ${ }^{25}$ 1999 Hupp $^{21}$ 2005).

Caso o paciente desenvolva uma reaçáo alérgica, devese avaliar sua gravidade. Sendo o problema uma simples reaçáo cutânea, a administração de corticoide ou antihistamínico (bloqueiam os receptores de histamina nos órgão-salvos) pode ser suficiente. Já no caso de uma reação cutânea mais grave, ambos podem ser administrados. Se a alteração evoluir para uma leve dificuldade respiratória que demorou um certo tempo para ocorrer, as duas medicaçóes citadas anteriormente podem ser suficientes. Entretanto, se o desconforto respiratório evoluir rapidamente, e o paciente se tornar dispineico, é essencial a administração de adrenalina $(0,3 \mathrm{ml})$. Na ocorrência de choque anafilático, deve-se administrar anti-histamínicos, adrenalina e oxigênio $(6 \mathrm{~L} / \mathrm{min})$ e solicitar o transporte do paciente para centro hospitalar (Andrade et.al. ${ }^{1}$ 2004, Marzola ${ }^{25}$ 1999, Hupp ${ }^{21}$ 2005).
É importante que o cirurgiāo-dentista trabalhe em conjunto com um auxiliar. Além da grande ajuda durante a prática clínica, o auxiliar, em casos de emergência/ urgência, desempenha atribuiçóes tais como, suporte para a administração de medicaçóes enterais e parenterais, manobras de ressuscitação cardiopulmonar se forem necessárias, assim como na solicitação de ajuda médica e de transporte para um centro hospitalar. Para isso, o auxiliar deverá ter um treinamento adequado, permitindo, dessa forma, que o profissional dedique-se exclusivamente ao tratamento do seu paciente.

Existe, ainda, um déficit, na maioria das faculdades de Odontologia, relacionado ao ensino de urgências médicas no consultório. Não existe um treinamento adequado para esse tipo de situação, nem um incentivo de uma aprendizagem continuada. Lembre-se que o hábito de realizar o procedimento resultará em maiores possibilidades de se obter sucesso em sua realização (Andrade et.al. ${ }^{1}$ 2004, Loureiro et al. ${ }^{23}$ 2004, Nagao-Dias et al. ${ }^{27}$ 2004, Ribeiro e Rosário ${ }^{29}$ 1992). O indício na melhoria desse aspecto é a obrigatoriedade da disciplina de urgência nos cursos de especialização.

\section{CONSIDERAÇÕES FINAIS}

As reaçóes alérgicas requerem dos profissionais de Odontologia o conhecimento da fisiopatologia e dos fatores predisponentes para o seu acontecimento e como lidar com seus graus de complexidade. $\mathrm{O}$ cirurgiãodentista deve possuir um conhecimento sobre a melhor escolha medicamentosa para cada paciente, com a finalidade de evitar qualquer tipo de reação alérgica. 
Gaujac C, Oliveira AN, Barreto FAM, Salgado LM, Oliveira MS, Girão RS. Reações alérgicas medicamentosas no consultório odontológico. Revista de Odontologia da Universidade Cidade de São Paulo 2009 set-dez; 21(3): 268-76

\section{REFERÊNCIAS}

1. Andrade ED, Costa CP, Ranali J. Reações alérgicas. In: Andrade ED, Ranali J. Emergências médicas em odontologia. $2^{a}$ Ed. São Paulo: Artes médicas; 2004.

2. Antunes AA, Genu PR, Medeiros MF, Vasconcelos RJH. Conhecimento dos alunos de graduação da FOP/UPE em relação à dosagem anestésica local. Rev Cir Traumatol Buco-Maxilo-fac 2007 jan-mar; v.7(1): 71-8.

3. Amaral JLG, Araújo LMT. Allergy to Lidocaine. case report. Rev Bras Anestesiol 2004 Sep-Oct; 54(5): 672-6.

4. Araujo MR, Azevedo LR, Castro LFA, Grécio AMT, Machado MAN, Mattioli T. Reações adversas medicamentosas de interesse odontológico. Rev Odontol Araçatuba 2005 jul-dez; 26(2): 28-33.

5. Becker DE, Reed KL. Essentials of local anesthetic pharmacology. Anesth Prog 2006; 53(3): 98-108; quis 109-10.

6. Bricks LF, Silva CAA. Recomendações para o uso de antinflamatórios não hormonais em pediatria. Pediatria (São Paulo) 2005; 27(2): 114-25.

7. Bricks LF. Analgésicos, antitérmicos e antiinflamatórios não-hormonais: controvérsias sobre sua utilização em crianças: parte III. Pediatria (São Paulo)1998 jul-set; 20(3): 230-46.

8. Brito FS, Cáceres MTF, Darrieux FC, Hachull DT, Ludovice ACPP, Neves RS, Scanavacal MI, Sosa et al. Efeito de anestésicos locais com e sem vasoconstritor em pacientes com arritmias ventriculares. Arq Bras Cardiol. 2008 Sep; 91(3): 142-7.

9. Campbell JR, Campbell RL, Maestrello CL. Allergic response to metabisulfite in lidocaine anesthetic solution. Anesth Prog. 2001; 48(1): 21-6.

10. Canfield DW, Gage TW. A guideline to local anesthetic allergy testing. Anesth Prog. 1987 Sep-Oct; 34(5): 157-63.

11. Chahade WH, Giorgi RDN, Szajubok JCM. Antiinflamatórios não hormonais. Einstein (São Paulo) 2008; 6 (Supl 1): S166-S74.
12. Criado PR, Criado RFJ, Gonçalves AC, Ramos ROR, Vasconcelhos C. Severe cutaneous adverse reactions to drugs - relevant aspects to diagnosis and treatment - Part I: anaphylaxisand anaphylactoid eactions, erythroderma and theclinical spectrum of Stevens-Johnson syndrome \& toxic epidermal necrolysis; Lyell's disease. An Bras Dermatol 2004 jul-ago; 79(4): 471-88.

13. Dale MM, Rang HP, Ritter JM. Farmacologia. 4.ed. Rio Janeiro: Guanabara Koogan; 2001.

14. Duarte VA, Duarte VA, Elias R, Fadel F, Guitmann J. Farmacologia aplicada na odontologia - antibiótico. [periódico na internet] [acesso em 2008 dez 12] Disponível em: http://www.odontosites. com.br/odonto/default2.asp?s=artigos2. asp\&id $=37 \&$ titulo $=$ Farmacologia $\% 20$ Aplicada $\% 20$ na $\% 20$ Odontologia $\% 20-\% 20$ Antibiótico.

15. Escobar CAB, Gerlach RF, Santos, JET. The use of epinephrine-containing anesthetic solutions in cardiac patients: a survey. Rev Odontol Univ São Paulo 1998 Oct-Dec; 12(4): 349-53.

16. Fang L, Fazio RC, Sonis ST. Princípios e prática de medicina oral. 2.ed. Rio de Janeiro: Guanabara Koogan; 1996.

17. Ferreira BLA. Identificação da atividade antibiótica e relação estrutura-atividade de moléculas de origem sintética e animal. [Mestrado] Rio de Janeiro: Universidade Federal Fluminense; 2007.

18. Gaujac C. Controle da dor e inflamação em cirurgia odontológca. [Mestrado] Araçatuba: Universidade Estadual Paulista, Faculdade de Odontologia de Araçatuba; 2006.

19. Grisi S, Miyake RS, Reis AG. Sedação e analgesia em crianças. Rev Ass Med Bras 1998 jan-mar; 44(1): 5664.

20. Grumach AS, Rosário NA. Allergy to beta-lactams in pediatrics: a practical approach. J Pediatr. (Rio de Janeiro) 2006 Nov; v. 82(5 suppl): 5181-8.

21. Hupp JR. Prevenção e tratamento das emergências médicas. In: Ellis E, Hupp JR, Peterson LJ, Tucker MR. Cirurgia oral e maxilofacial contemporânea. 4.ed. Rio de Janeiro: Elsevier; 2005. 
22. Kalghatgi S. Just to berries. Allergy to local anesthetics. Can Fam Physician. 2001 Jul; 47: 1391-3.

23. Loureiro CCS, Adde CA, Perez FEG, Penha SS. Efeitos adversos de medicamentos tópicos e sistêmicos na mucosa bucal. Rev Bras Otorrinolaringol 2004 jan-fev; 70(1): 106-11.

24. Malamed ST. Manual de anestesia local. 5. ed. Rio de Janeiro: Mosby; 2005.

25. Marzola C. Anestesiologia; 3. ed. São Paulo: Pancast; 1999.

26. Mertes PM, Laxenaire MC. Allergy and anaphylaxis in anesthesia. Minerva Anestesiol 2004 May; 70(5): 285-91.

27. Nagao-Dias ATN, Nunes PB, Coelho HLL, Solé D. Reações alérgicas a medicamentos. J Pediatr 2004 julago; 80(4): 259-66.
28. Nunes BC. Analgesia multimodal no tratamento da dor aguda. [Periódico na internet] [acesso em 2008 nov 28] Disponível em: http://www.saj.med.br/ uploaded/File/novos_artigos/124.pdf.

29. Ribeiro AC, Rosário NA. Achados clínicos da sensibilidade a analgésicos e antiinflamatórios não-hormonais. Rev Ass Med Bras (1992). 2000 jul-set; 46(3): 201-6.

30. Roberts DH, Sowray JH. Analgesia local em odontologia. 3. ed.; São Paulo: Santos; 1995.

31. Sobreira CR, Zampier MR. Terapia farmacológica nas desordens temporomandibulares. Rev Un Alfenas 1999; 5: 239-245.

32. Villaça-Neto CM, Abede JRZ. Anestesia - parte I. An bras Dermatol. 1999 maio-jun; 74(3):213-9.

Recebido em: 1/9/2009 Aceito em: 1/10/2009 